\title{
Mídia e diferentes dimensões da Accountability
}

\author{
Rousiley C. M. Maia1 \\ UFMG
}

\begin{abstract}
Resumo: Tem-se como propósito examinar as possibilidades e os obstáculos da visibilidade midiática para desencadear processos políticos, legais e profissionais de accountability. A abordagem aqui realizada considera que o jornalismo não só se apresenta como instância na qual os discursos dos atores sociais adquirem visibilidade, isto é, tornam-se disponíveis ao conhecimento público, mas, também, o concebe como um fórum para o debate cívico, constrangendo os interlocutores a se posicionarem diante de uma audiência ampliada. Examina-se a emergência e a transformação das interpretações sobre um evento específico: o seqüestro do ônibus 174, ocorrido no Rio de Janeiro, no ano 200o, o qual foi televisionado durante quatro horas ininterruptas e expôs um caso de extrema violência urbana à atenção pública. Busca-se evidenciar, através dos padrões dialógicos promovidos pelos atores sociais que foram chamados a se expressar sobre o evento, a existência ou não de troca de razões e uma responsividade mútua entre eles.
\end{abstract}

Palavras-chave: accountability, mídia, deliberação pública, violência urbana

\begin{abstract}
This paper aims at examining the potentiality of mediated visibility in unleashing political, legal and professional processes of accountability. The news media are approached as a forum for civic debate which constrains interlocutors to speak before a large audience. Upon examining the emergence and transformation of the interpretations of a specific event - the hijacking of the 174 Bus, that occurred in Rio de Janeiro in 2000 - broadcast live for four hours. This happening exposed a case of extreme urban violence to public view and compelled political representatives, public officials and organizations of civil society to exchange views about the so-called crisis of the government in maintaining public security. We evince patterns of public dialogue and reason exchange as put forth by sources, whether there is or not mutual responsiveness amongst them in the news media.
\end{abstract}

Key words: accountability, public deliberation, journalism, urban violence.

1 Rousiley C. M. Maia, doutora em Ciência Política pela University of Nottingham (Inglaterra), é professora no Departamento de Comunicação Social da UFMG, e pesquisadora, nível 1D, do CNPq. 


\section{Democracia, Accountability e Mídia}

A questão da accountability é fundamental para a qualificação da democracia moderna. Ela acarreta para os representantes políticos, na organização de seus poderes e obrigações, o dever de responder aos cidadãos, de replicar às críticas a eles endereçadas e de aceitar (alguma) responsabilidade sobre suas falhas, incompetência ou desonestidade. $O$ jornalismo tem sido tratado, desde Edmund Burke, Jeremy Bentham e James Mill, como um dos atores clássicos capazes de promover controle na partilha de poder, através de mecanismos de checks and balances, mantendo o governo accountable na ordem democrática. Particularmente, o jornalismo investigativo, em sua função de "cão de guarda", procura monitorar as autoridades, seja nas instituições do governo, seja em organizações sociais do setor privado (Dennis, Gilmor e Glasser, 1989; Schudson, 1995; Curran, 2000; Norris, 2000; Waisbord, 2000). Ao expor, ao conhecimento geral, escândalos que afetam o bem comum, falhas governamentais ou transgressões de poder, a imprensa e seus porta-vozes compelem os agentes concernidos a providenciar respostas e justificativas às críticas a eles dirigidas (Waisbord, 2000; Thompson, 2000; Slako, 2002). Aqueles que demandam accountability exigem respostas e justificativas, enquanto aqueles que se mantêm accountable aceitam responsabilidades e provêm explicações. Nesse sentido, o jornalismo permite tanto confrontos diretos ou virtuais entre os atores sociais quanto uma troca de pontos de vista no espaço de visibilidade midiática. ${ }^{2}$

No contexto do Estado democrático, o processo de accountability ocorre entre os cidadãos e os ocupantes de posições públicas, entre e dentre classes hierárquicas de representantes oficiais, políticos eleitos e os representantes de instituições burocráticas. Para nossos propósitos, interessa enfatizar que os discursos dos atores sociais adquirem

2 Por "visibilidade midiática", entendo simplesmente o "espaço do visível" (Thompson, 1995, p. 245) constituído pelo aparato tecnológico da mídia, de modo que um conjunto de formas simbólicas - sentenças, ações, imagens e eventos - pode ser estendido no tempo e no espaço. Através das emissões midiáticas, essas formas simbólicas podem ser tornadas públicas, "publicizadas, compartilhadas e socialmente acessíveis", como afirma John Dewey [1927] (1954, p. 176-184). Nas palavras de Dahlgren, "a mídia de massa contribuiu [para criar] espaços de visibilidade pública onde o mundo e suas questões atuais estão, através de vários modos de representação, disponíveis para a maioria dos cidadãos" (2001, p. 37). Na verdade, o acesso ao "espaço de visibilidade midiática" requer a especificação de indicadores observáveis das emissões dos meios de comunicação, seus formatos, modos de operação e seus produtos. 
"publicidade" através da mídia, tornando-se disponíveis ao público. Os interlocutores são incitados a responder por seus atos "não só uns frente aos outros, mas também diante de uma audiência de cidadãos, o público em geral" (Gutmann e Thompson, 1996, p. 137). Evidentemente, essa é uma atividade que nem sempre resulta, na prática, em um diálogo aberto entre a administração pública e seus públicos. Muitas vezes, as pessoas envolvidas em transgressões evitam uma comunicação franca e transparente, com a intenção de proteger interesses particulares ou corporativos, precisamente por razões não-públicas. Após a revelação feita pela imprensa, as instituições responsáveis podem ser ineficazes ou não demonstrarem interesse em conduzir investigações futuras. Meu argumento, neste artigo, é o de que seria restritivo avaliar o desempenho do jornalismo somente quando acusações resultam em processos de investigação bem sucedidos e em punição efetiva. Mesmo quando o procedimento da accountability falha, a prática de trocar pontos de vista publicamente, para alcançar soluções corretas em circunstâncias de conflito, é importante para expandir debates públicos e abrir o caminho para a inovação institucional.

A fim de examinar práticas de accountability expressas na esfera de visibilidade pública, explorarei um evento específico - o seqüestro do ônibus 174, ocorrido no Rio de Janeiro no ano 2000. O seqüestro foi transmitido ao vivo durante quatro horas seguidas pela principal emissora de televisão brasileira, a Rede Globo, e também pela CNN que, por sua vez, disponibilizou as imagens em rede mundial. $O$ poder das imagens é particularmente relevante para a constituição pública desse evento. Se não fosse pela presença das câmeras, é possível supor que o acontecimento não teria provocado a comoção pública que causou. Ao notar a presença das câmeras de TV, o próprio seqüestrador estabeleceu estratégias de comunicação com o público: ele força uma das reféns a escrever com um batom, no pára-brisa do ônibus, frases como, "ele vai matar todo mundo"; encena dramatizações de maus tratos às vítimas e simula a morte de outra refém, ordenando que o grupo demonstrasse pânico. Sem a presença das câmaras de TV, a polícia também poderia ter agido sem chamar a atenção pública. No entanto, o seqüestro do ônibus tomou proporções de um evento público, com características de um "espetáculo", exatamente por causa de sua audiência, estimada em 54 milhões de espectadores. Imediatamente após o fim do seqüestro, o Presidente da República fez um 
pronunciamento em cadeia nacional, através da televisão aberta. Na principal cobertura dos noticiários, os jornalistas convidaram o Governador do Rio de Janeiro, várias autoridades públicas, membros da corporação policial, assim como representantes de movimentos sociais que lutam contra a violência, a comentar o evento e a prover interpretações sobre as responsabilidades envolvidas no episódio.

Pode-se indagar por que um seqüestro de ônibus provoca mecanismos de accountability. Por que o Presidente é chamado a prestar contas, se os meios de comunicação divulgam um crime? Certamente, a forte dramaticidade do episódio não é condição suficiente para deslanchar mecanismos de prestação de contas, a ponto de motivar o próprio presidente a fazer um pronunciamento público. No entanto, em um contexto de violência urbana indiscriminada e de altos níveis de criminalidade (Caldeira, 2000; IPEA, 2003, p. 89), o evento expõe não só o infortúnio dos passageiros do ônibus 174, mas a insegurança e o risco que acomete a todos os que precisam utilizar-se das calçadas e das vias públicas, nas metrópoles brasileiras. A violência urbana aparece como um dos problemas mais sérios do país - um fenômeno captado e refletido nas pesquisas de opinião como algo que apresenta um crescimento aparentemente inabitual e incontrolável ${ }^{3}$. Assim sendo, o seqüestro do ônibus 174 se apresenta como exemplo emblemático de uma "situação problema" - a qual é envolvida por um conjunto de circunstâncias e condições estruturalmente deficientes ou não-solucinadas, passíveis de gerar alarme, risco ou medo (Queré, 1995, p. 106).

Uma combinação de fatores contribuiu para conferir a esse evento uma notória repercussão nacional e internacional: 1) a transmissão ao vivo permitiu que a violência em ação pudesse ser "vista e ouvida por todos"; 2) o cerco ao ônibus feito pelo policiais, seguida por uma negociação "desastrosa" - terminando com um policial atirando numa refém - foi considerada uma "série de falhas"; 3) a morte do seqüestrador dentro do carro da polícia a caminho da delegacia foi classificada como um claro exemplo de abuso da autoridade policial; 4) a descoberta, posterior, de que o seqüestrador era dos sobreviventes

3 Vários estudos sobre a criminalidade urbana têm apontado que não podemos estabelecer uma ligação direta entre um perceptível "aumento da violência" e a repentina explosão da violência (Adorno, 1998; Beato, 2001; Sapori, 2001; IPEA, 2003). 
de um evento que causou grande ultraje público em 1993 - a "Chacina da Candelária", ocorrida em 1993, caso de extrema brutalidade, em que crianças de rua são executadas por policiais - reafirmou as causas complexas da criminalidade no país (Piault, 2004, p. 37; Pinheiro, 2004). A despeito de o desfecho do seqüestro poder ser interpretado como um procedimento normal de trabalho das instituições policiais e suas táticas operatórias - que, na verdade, nunca funcionaram bem - o que é mais evidente nos meios de comunicação é a interpretação do evento como uma evidência clara de uma forte crise institucional. Como diferentes tipos de accountability - política, legal ou profissional - se desdobram na esfera de visibilidade pública, constituída pelos meios de comunicação? Quem responde a quem? Há uma responsividade mútua entre os atores convocados a se pronunciar, ou seja, eles explicam e justificam suas ações ao se verem diante de críticas? Antes de responder a essas questões, é preciso examinar mais detidamente o conceito de accountability.

\section{Explorando as diferentes dimensões da Accountability}

A accountability não é, em si mesma, uma norma ou uma justificação normativa de qualquer assunto, mas um meio de reforçar a norma democrática (Manin, 1997; Arato, 2002). Enquanto um sistema de direitos e obrigações, a democracia pressupõe que "o poder público é regulado por normas gerais (leis fundamentais ou constitucionais) e precisa ser exercido através do quadro normativo de leis que o regulam, enquanto os cidadãos têm seus direitos assegurados por um poder judiciário independente, a fim de estabelecer e prevenir abuso ou uso excessivo de poder" (Bobbio, 1988, p. 12). Num sentido amplo, accountability refere-se ao imperativo democrático de que os representantes devem considerar os desejos e as necessidades dos cidadãos na condução dos negócios públicos. Independentemente da existência de um controle formal, um governo é considerado "responsivo" se ele adota políticas que são apontadas pelos cidadãos como as favoritas (Przeworski, Stokes e Manin, 1999, p. 9). Numa dimensão normativa, a questão da accountability estabelece uma estreita relação com a legitimidade - a propriedade de que os procedimentos de um regime para fazer e implementar a lei sejam aceitos por seus sujeitos. No entanto, o problema da accountability também inclui a busca por mecanismos institucionais destinados a controlar o desempenho das instituições públicas e a julgar o 
modo pelo qual os representantes e os agentes públicos agem concretamente na disposição de seus poderes e deveres.

As decisões políticas são tomadas pelos representantes eleitos e implementadas por agentes públicos, a quem os representantes delegam algumas das tarefas do governo. As instituições democráticas devem oferecer, assim, mecanismos horizontais de accountability: "poderes distintos do governo respondem e prestam contas não apenas aos cidadãos, mas uns aos outros" (Przeworski, Stokes \& Manin, 1999, p.19). Isso exerce uma coerção adequada, uma vez que os encarregados do governo ficam sujeitos a dar explicações a seus superiores, tendo em vista suas ações e o uso que fazem de poderes delegados. Se as normas forem infringidas ou se houver transgressão de poder, representantes e agentes públicos devem aceitar sanções legítimas. A accountability legal é conectada ao sistema jurídico e não às pessoas, mas ela diminui a distância entre aqueles que produzem as regras e aqueles que a elas se submetem, sendo um dos instrumentos fundamentais do constitucionalismo (Arato, 2002, p. 93).

Vários autores (Romzek e Dubnick, 1987; Przeworski, Stokes e Manin, 1999; Mulgan, 2000) mostraram que o conceito de accountability desdobra-se em diferentes questões analíticas referentes a: a) accountability como responsividade - o modo pelo qual os dirigentes procuram satisfazer os desejos e as necessidades dos cidadãos, adotando políticas que são sinalizadas como aquelas mais desejáveis por estes, embora não haja um controle formal; b) accountability como controle - o uso de vários mecanismos e métodos de "checksand-balances", destinados a regular e supervisionar o desempenho de organizações públicas e os atos de seus agentes; c) accountability profissional ou pessoal - o sentido interiorizado de responsabilidade individual diante do interesse público, em uma dada situação, o qual inclui o desempenho consciente de funções e deveres; d) accountability como diálogo - a dimensão

$4 \quad$ Romzek e Dubnick (1987) propõem uma distinção entre diferentes formas de accountability, obedecendo à fonte de controle (interna ou externa) e ao grau de controle exercido sobre os agentes políticos (alto ou reduzido). Tais formas são: a accountability burocrática-com um grande potencial de controle interno - origina-se de arranjos hierárquicos baseados na supervisão e na organização de diretrizes. A accountability legal - com um grande potencial de controle externo - é garantida através de arranjos contratuais. Pares e grupos de trabalho são a base da accountability profissional - com um baixo controle interno - sob a observação de competências. A accountability política - com um baixo potencial de controle externo - é estabelecida pela capacidade dos representantes de prestar contas e prover explicações. 
corrente na troca dialógica, quando os interlocutores assumem responsabilidade por seus próprios pronunciamentos e respondem às indagações dos outros, mesmo quando não há nenhuma relação formal de autoridade e subordinação entre as partes envolvidas.

$\mathrm{Na}$ prática, essas são dimensões interconectadas, implicando interações e trocas sociais. Por essa razão, Andrew Arato defende que "o regime de accountability não pode ser algo puramente procedimental" (Arato, 2002, p. 92). Em primeiro lugar, é por meio do diálogo que os cidadãos (indivíduos e grupos) verbalizam demandas e expectativas através de fóruns cívicos de discussão, de sondagens deliberativas, ou através da mídia de massa (Bohman, 1996; Fiskin, 1997; Gutmann e Thompson, 1996). Em segundo lugar, a especificação de uma dada norma e sua aplicação, em cada situação de mau-uso do poder ou de transgressão, depende, geralmente, da consideração de vários pontos de vista, envolvendo discussão entre diversos atores sociais (Roberts, 2002). Além disso, não se pode adotar uma "visão realista" do mecanismo de controle, como se as regras estivessem necessariamente claras desde o início e as interpretações das ações praticadas fossem relativamente consensuais. Por isso, o debate crítico é tido como algo fundamental para a sustentação do regime de accountability. "Um regime de accountability somente pode funcionar bem ao lado da deliberação ${ }^{5}$ que ocorre na esfera pública, e é sustentado pela sociedade civil”' (Arato, 2002,p. 96).

$\mathrm{Na}$ sociedade contemporânea de larga escala, os meios de comunicação são importantes para tornar visível o processo de accountability, a fim de que ele seja reconhecido e apreciado pelos cidadãos comuns. Com bem sabemos, os media não são meros canais neutros para outras fontes, mas, sim, organizações que controlam o acesso dos atores sociais aos seus canais e regulam os fluxos de comunicação. Os profissionais da mídia selecionam e editam eventos e discursos, enquadrando significados a partir da própria lógica e de seus modos operatórios. As operações jornalísticas não devem ser vistas

$5 \quad$ Habermas (1996), Cohen (1997), Bohman (2000); Gutmann e Thomposn (1996, 2004) enfocaram, apesar das diferenças em suas respectivas abordagens, a deliberação como um processo envolvendo a interação e a cooperação, no movimento de oferecer e examinar argumentos. "A deliberação é uma atividade social conjunta, enraizada na ação social do diálogo o dar e receber razões” (Bohman, 2000, p. 32). Nas palavras de Gutmann e Thompson (2004, p. 7), "cidadãos livres e iguais (e seus representantes) justificam decisões em um processo no qual oferecem, uns aos outros, razões que são acessíveis de forma mútua e geral, com o objetivo de chegar a conclusões que são atualmente vinculantes, mas abertas a revisões posteriores". 
como resultantes de escolhas conscientes de repórteres individuais, mas, sim, como algo enraizado nas rotinas da profissão e da organização das agências noticiosas (Tuchman, 1978; Schudson, 1995; Meyer, 2002; Reese et al., 2003). Aquilo que é dado a ver na esfera de visibilidade pública constituída pelos meios de comunicação é, com freqüência, o resultado da competição entre os agentes sociais, com intento de influenciar a percepção pública dos eventos, e, também, destes com os próprios agentes da mídia (Gamson e Modigliani, 1989; Meyer, 1995; Page, 1996; McAdam, 1996; Pan e Kosicki, 2003). Nessa perspectiva, meu interesse é analisar a emergência e a transformação das disputas acerca do evento do ônibus 174 na própria esfera de visibilidade midiática, e apreender se há troca mútua de razões entre as fontes, e se a reversibilidade das opiniões proferidas se dá.

Métodos diferentes de pesquisa foram empregados neste trabalho. Embora as imagens do seqüestro gravadas "ao vivo" pela Rede Globo tenham sido examinadas, o resultado dessa análise não será apresentado aqui ${ }^{6}$. Neste artigo, uma atenção especial é conferida à cobertura principal das notícias de modo a acessarmos diferentes tipos de accountability - política, legal e profissional - que se desenvolvem na mídia impressa. Todos os artigos referentes ao seqüestro foram coletados de dois dos maiores jornais diários nacionais e de três revistas semanais de maior relevância, no período de 13/06/00 a 22/06/00, ou seja, dez dias após o evento. Após excluir as cartas aos editores e as menções tangenciais nos artigos referentes a outros tópicos, nosso corpus de análise ficou composto por 128 artigos assim distribuídos: 55 do Estado de Minas; 66 da Folha de São Paulo; 2 da Veja; 2 da Época. O seqüestro foi matéria de capa em todas essas revistas semanais.

Para explorar o material acima descrito, empregamos uma análise de conteúdo para identificar as polêmicas relevantes, presentes nos textos das notícias e distinguir entre diferentes fontes mencionadas (identificadas por nome, status e pertencimento social). Em segundo lugar, as fontes foram classificadas segundo certas categorias: a) representantes do governo (membros do executivo, do judiciário e do legislativo); b) agentes oficiais da corporação policial; c) especialistas de diferentes campos; d) membros da sociedade civil organizada e não-organizada. Tal classificação deu origem a um mapa das "vozes" e

\footnotetext{
$6 \quad$ Além das imagens ao vivo gravadas, o documentário "Ônibus 174", de José Padilha, produzido em 2002, também foi utilizado.
} 
"posições" assumidas por diferentes fontes, considerando polêmicas e questões relevantes. Finalmente, uma análise de discurso foi desenvolvida para mostrar as explicações e justificações promovidas por indivíduos situados em diferentes posições do sistema político. O objetivo foi o de evidenciar padrões de troca dialógica, uma eventual responsividade e a reversibilidade de opiniões que ocorreram entre os atores políticos, por meio da mídia impressa. Nesse procedimento, segui parcialmente as análises de Tuchman (1978) e de Bennett $(1990,2003)$ acerca da construção da legitimidade jornalística por meio da dependência em relação aos pronunciamentos oficiais das autoridades do governo, conferindo, também, atenção às vozes da sociedade civil, num dado sistema político e contexto de discussão.

\section{Accountability como o dever de responder às expectativas necessidades dos cidadãos}

A demanda para que os governantes ou representantes oficiais sejam publicamente accountable por seus atos - seja no âmbito legislativo, nos tribunais ou nos media - força-os a se engajarem em um tipo de diálogo com o público. Os media estendem aos outros, de uma maneira mais ampla do que aquela que seria possível em interações face a face ou pessoais, o potencial para que os representantes sejam responsáveis (answerable) por suas ações e seus proferimentos. Em seu pronunciamento, logo após o encerramento da transmissão do seqüestro, o então presidente da República diz que estava sensibilizado com os efeitos danosos daquela "violência absolutamente inaceitável".

Nós acabamos de assistir, todos estarrecidos, durante horas, a uma cena de um seqüestro de uma pessoa aparentemente drogada, numa violência absolutamente inaceitável e até certo ponto contristados por não ver uma ação mais rápida que fosse capaz de evitar o desenlace fatal de uma jovem absolutamente inocente [...]. ${ }^{7}$

E eu, como presidente da República, não poderia deixar de dar uma palavra de solidariedade, primeiro à família, mas, também, ao povo sofrido das cidades do Brasil. ${ }^{8}$

\footnotetext{
7 FHC. Folha de S. Paulo, 13 jun. 2000, C2, Cotidiano.

$8 \quad$ FHC. Folha de S. Paulo, 13 jun. 2000, C2, Cotidiano.
} 
O presidente Fernando Henrique Cardoso interpela os telespectadores como parte de uma mesma comunidade política, a de "todos os brasileiros" - um de nós - que sente "um misto de pavor e indignação com o que estava acontecendo". A modernidade expropriou a experiência da violência da vida ordinária. Se atos de violência - a tortura, o suplício do corpo, a brutalidade - continuam obviamente existindo, eles ocorrem geralmente longe do olhar do público, da audiência em grande número. $\mathrm{Na}$ sociedade democrática, a violência causa indignação porque ela se apresenta como algo que não deveria ocorrer, e outro tipo de ordem parece dela resvalar (Arendt, 1985). Reportagens envolvendo violência e cenas de corpos flagelados evocam diferentes formas de afecção emocional em diferentes grupos sociais (Hauser, 2000; Höijer, 2004, p. 523-40). Contudo, qualquer um poderia, aparentemente, se ver no lugar das vítimas. O próprio Presidente da República, em seu pronunciamento à mídia, coloca-se no papel implícito do outro: "há sempre uma tragédia pessoal por trás das estatísticas sobre a violência [...] Qual de nós não sofreu, diretamente, a ação dessa violência?"10 $\mathrm{O}$ governador do Rio também assume tal papel: "Não queria estar no lugar de nenhum dos passageiros [...] Essa menina poderia ser minha filha" ${ }^{\prime 11}$.

O evento do ônibus 174 faz indagar, em particular, a respeito da eficácia do governo em prover a ordem social e a segurança pública. Desde o surgimento das primeiras teorias do Estado Moderno, reconhece-se que a finalidade mínima de um governo é proporcionar as condições que permitam a coexistência pacífica entre grupos e indivíduos, impedindo ações violentas. Através da ordem jurídica, os indivíduos são expropriados da utilização da violência para atingir seus fins pessoais, ficando o Estado como detentor do monopólio do uso legítimo da violência, a fim de prover proteção pública aos cidadãos, contra os custos da ameaça criminosa. A polícia, como a instituição de controle social por excelência, se encarrega de inibir ou reprimir os delitos contra a pessoa, contra a propriedade e contra a lei comum. Na Constituição Brasileira, a Segurança Pública é definida como "dever do Estado, direito e responsabilidade de todos".

\footnotetext{
$9 \quad$ FHC. Estado de Minas, 14 jun. 2000. Caderno Política, p. 8.

10 FHC. Estado de Minas, 21 jun. 2000. Caderno Política, p. 3.

11 Garotinho. Folha de S. Paulo, 13 jun. 2000. Caderno Cotidiano, p. C4.
} 
Nesse sentido, o seqüestro do ônibus 174 suscita a prestação de contas do próprio Presidente, que oferece explicações dirigidas ao público. Isso significa, de certa maneira, que ele está ciente de suas obrigações morais e políticas, de solucionar os problemas que afetam a vida social.

Isso impõe a todos nós brasileiros e, sobretudo, a nós, que temos responsabilidade de governo, a necessidade de uma ação conjunta, mais eficaz, para combater a violência, o crime, a droga, porque estamos chegando a um ponto que é inaceitável. ${ }^{12}$

A violência urbana é um problema complexo, que não dispõe de uma solução específica, uma vez que o Estado, apenas, não é capaz de garantir a pacificação das relações sociais. Fatores sócio-econômicos e sócio-culturais de segregação e exclusão social desencadeiam um conjunto de mecanismos, com uma rede de efeitos que se cruzam entre si (Zaluar, 1996, p. 53, 1999; Adorno 1998; Pinheiro, 1997; Belli, 2000). Não obstante, os representantes são responsáveis pelas políticas que sustentam e, também, pelas suas conseqüências (Gutmann e Thompson, 1996, p. 137). Nesse sentido, o presidente sustenta a expectativa de ser ele o responsável pelos outros agentes, dentro do sistema político. Ele reafirma que, apesar de os governos estaduais serem diretamente responsáveis pela segurança pública, as autoridades federais, "no âmbito de suas ações", já estavam "reunindo forças para impulsionar um programa de emergência, uma vez que a violência assistida pelo Brasil demanda medidas rápidas"13. O Presidente propõe, nesse âmbito, que os "representantes oficiais formem um mutirão de combate à violência, para agir com mais energia a fim de coibir esses atos, que são francamente assustadores" ${ }^{\text {"14}}$ :

Com todas as dificuldades que existem, nós temos que nos dar as mãos: os governadores, o presidente da República, as forças de segurança, as Forças Armadas, no que lhes corresponde, para pôr um paradeiro a essa onda de violência que tem no crime organizado, na droga, as molas fundamentais. Acho que o país não agüenta mais. ${ }^{15}$

\footnotetext{
12 FHC. Folha de S. Paulo, 13 jun. 2000, Cotidiano, p. C2.

13 FHC. Folha de S. Paulo, 13 jun. 2000. Cotidiano, p. C2.

$14 \quad$ FHC. Folba de S. Paulo, 13 jun. 2000, Cotidiano, p. C2.

15 FHC. Folba de S. Paulo, 13 jun. 2000. Cotidiano, p. C2.
} 
Seguindo a via institucional, nota-se que o Presidente da República, em seu discurso televisionado, demanda que os agentes públicos solucionem o problema:

O governo federal entrará em contato de imediato, como já fiz hoje, com o governador do Rio de Janeiro, que naturalmente me disse que eles estavam fazendo o que lhes correspondia e eu disse que estava preparado para ajudar no que ele necessitasse. Mas eu sei que, nessas horas, depende da ação direta de quem tem o comando sobre a polícia. ${ }^{16}$

A democracia representativa, como já apontado, configura-se como uma cadeia de delegação de competências e uma correspondente cadeia de accountability que opera na direção oposta (Manin, 1997). Apesar de apresentar algumas dificuldades conceituais, tal noção contribui para mostrar os mecanismos que permitem aos mandatários fazer com que os agentes públicos sejam responsabilizados (accountable ex post), pelo real funcionamento das instituições, no sistema democrático. Manter o governo aberto e accountable não é fácil. Obviamente, aqueles que se encontram envolvidos em transgressões não querem oferecer voluntariamente informações sobre erros ou abuso de poder. Os jornalistas intentam estampar informações que os políticos e as autoridades públicas pretendem manter em segredo (Waisbord, 2000; Thompson, 2000). Contudo, o governo não é uma instância monolítica. Como veremos, os representantes do governo, ligados aos diferentes poderes do sistema político, tomaram diferentes posições para interpretar o episódio do ônibus 174. Conscientes da importância da comunicação política, as autoridades políticas exercem, na esfera de visibilidade pública, uma pressão distinta sobre os membros da corporação policial.

\section{Accountability e avaliação retrospectiva}

No evento do ônibus 174, a primeira polêmica se desenrolou em torno da "conturbada" operação dos policiais, instaurando uma controvérsia acerca da eficácia da policia em prover a ordem - incluindo o conjunto de expectativas sobre o desempenho da corporação e sobre as responsabilidades individuais (Hunold, 2001; Roberts, 2002, Romzek e Dubnick, 1987). O primeiro pronunciamento oficial de "quem tem o comando sobre a

16 FHC. Folba de S. Paulo, 13 jun. 2000. Cotidiano, p. C2 e C4.; Estado de Minas, 21 jun. 2000. Nacional, p. 7. 
polícia”, o Governador do Rio, é apresentado através de uma nota à imprensa, logo após o encerramento do seqüestro. $O$ governador lamenta a morte da refém e reconhece o desempenho da polícia como satisfatório:

[...] a assessoria de imprensa de Garotinho informou que o governador 'sentiu-se aliviado' com o desfecho, que ele elogiara a atuação enérgica da polícia e que ele havia considerado que o final do seqüestro havia sido 'a melhor solução possível'. ${ }^{17}$

No dia seguinte, o governador declara que o desfecho não agradou nem a ele, nem ao comandante da operação e "a falha foi ter morrido alguém" "18. Também o secretário de segurança pública do Rio afirma, de maneira bastante ambígua, que os policiais deixaram de corresponder ao desempenho esperado: "a ação do soldado foi inoportuna, ele fez uma avaliação errada, mas se tivesse matado Nascimento e a moça não fosse atingida por disparos a ação teria sido correta" ${ }^{\prime 19}$.

O primeiro passo para desencadear accountability é nomear algo como um problema (Pritchard, 2000). Não há exigência para explicação e justificação, a menos que alguém defina a questão como sendo algo impróprio, errado ou indesejável. Se, num primeiro momento, a morte da refém apresenta-se como um acidente ou uma fatalidade, novos discursos aparecem na esfera de visibilidade pública, alterando tal quadro interpretativo.

Os jornalistas acionam especialistas e membros da corporação policial - os quais possuem conhecimento e autoridade para escrutinar as técnicas e os procedimentos adotados por seus pares - para comentar a operação de resgate (Meyer, 2002; Schudson, 1995; Waisbord, 2000). Eles ressaltam que o processo de negociação foi "completamente equivocado"20 ${ }^{20}$ com erros de avaliação, com usos inadequados de equipamentos e confusão nas operações táticas.

Ao longo do debate, vai se tornando cada vez mais consensual a opinião de que a ação dos policiais foi “desastrosa", contendo "uma falha atrás da outra", uma "sucessão de

\footnotetext{
$17 \quad$ Folha de S. Paulo, 13 jun. 2000. Caderno Cotidiano, p. C4.

18 Garotinho. Folha de S. Paulo, 13 jun. 2000. Caderno Cotidiano, p. C3.

19 Josias Quintal. Folha de S. Paulo, 14 jun. 2000. Caderno Cotidiano, p. C6.

20 Coronel da PM, pesquisador de segurança do Instituto de Segurança Fernand Braudel, Veja, 21 jun. 2000, p. 44.
} 
erros" ${ }^{21}$. O então Ministro da Defesa afirma, em entrevista, que "o desfecho do episódio deixou claro o despreparo dos policiais envolvidos na operação",22. De maneira semelhante, o então Ministro da Justiça interpretou o episódio como uma demonstração de "quanto o Brasil está despreparado, pela ausência de técnica e competência, para enfrentar uma situação limite [...] o que se viu no desfecho foi que não havia rumo nem comando" ${ }^{\prime 23}$.

Uma vez nomeado o problema, o segundo passo do processo de accountability, segundo Pritchard (2000), é apurar responsabilidades, identificando os responsáveis pelas falhas cometidas. Apurar responsabilidades e imputar culpa não são processos coincidentes. Somente quando é possível estabelecer a responsabilidade de determinados atores constitui-se a terceira etapa da accountability, isto é, a conseqüente aplicação formal de punição ou a exigência de retratação. Antes da caracterização da ação da polícia como inadequada ou imprudente, os membros da corporação policial são instados a explicitar, sobre o acontecido, o que estava latente no entendimento geral, ou era simplesmente restrito a um pequeno grupo da corporação.

O jornalismo investigativo quebra o silêncio oficial sobre questões problemáticas e obriga as partes envolvidas a se expressarem. Todavia, os padrões de resposta da corporação policial indicaram alguns paradoxos das tentativas de manter os oficiais accountable (Harmon, 1995; Roberts, 2002, p. 659-660). Os policiais ressaltaram que agiram de acordo com uma regra legítima, seja a do código de conduta da corporação, seja a do Direito. Existe uma dificuldade particular em equacionar as responsabilidades pessoais, tendo em vista as conseqüências da ação, na situação concreta. Em diversas entrevistas, o comandante do Bope declara que não deu ordem aos soldados para atirar. Destaca que seus "homens são treinados para ter autonomia e tomar decisões" 24 . Por sua vez, membros da corporação buscam sustentar a inocência dos policiais, afirmando que exigiriam operações como aquela "a ação de forças especiais das polícias e não do efetivo que cuida do policiamento rotineiro" ${ }^{25}$. Eles ressaltam que os policiais não contavam com os recursos

\footnotetext{
$21 V$ Veja, 21 jun. 2000, p. 42-43; Folha de S. Paulo, 14 jun. 2000. Caderno Cotidiano, p. C12.

22 Geraldo Magela Quintão. Estado de Minas, 16 jun. 2000. Caderno Política, p. 5.

23 José Gregori. Estado de Minas, 16 jun. 2000. Caderno Política, p. 5.

24 Isto É, 21 jun. 2000, p. 30-32.

25 "Garotinho esteve durante todo o tempo em contato com o Secretário de Segurança
} 
necessários - aparelhagem técnica ou treinamento especializado qualificado - para atingir os objetivos da instituição. ${ }^{26}$ Eles tendem, também, a deslocar a responsabilidade individual para os atores coletivos, organizações e sistemas sociais, minando a base que permite imputar responsabilidades a agentes individuais pelas conseqüências da ação. Outra forma de justificação é baseada na diluição da responsabilidade entre vários membros do centro do sistema político (Roberts, 2002). Ao buscar responder quem seriam os verdadeiros responsáveis por aquela operação "sem rumo e sem comando", alguns membros da corporação policial apontam que representantes de escalões superiores do executivo exerceram um controle manipulador da autoridade política, impedindo uma atuação eficiente da corporação policial. "A PM não teve liberdade de agir porque o governador ficou dando 'piruada' (palpite) por telefone, ${ }^{, 27}$.

As decisões práticas que guiam a ação da polícia em sua rotina diária nem sempre são guiadas pela lei, como a visão legalista da ação policial nos levaria a acreditar. Apesar disso, as autoridades públicas - "que geralmente possuem um total conhecimento com relação aos constrangimentos legais" (Mulgan, 2000, p. 564) - quando chamadas a se expressarem em público, freqüentemente apresentam suas políticas e decisões de uma maneira a manter-se dentro dos limites legais impostos a elas. Devemos observar que, apesar de haver um acordo sobre a necessidade de fazer com que agentes particulares prestem contas de suas ações - como um aspecto fundamental a todas as tentativas de controlar o poder público -, julgar atos é uma tarefa difícil, mesmo quando os efeitos já se materializaram (Przeworski, Stokes e Manin, 1999, p. 23; Hunold, 2001, p. 161-163). Este é, particularmente, o caso de pares e equipes de trabalho que formam a base da accountability profissional - com baixo controle interno na observância da expertise.

\section{Accountability Legal}

Pública do Estado do Rio de Janeiro, Josias Quintal, que, por sua vez, do seu próprio gabinete, mantinha contato com o comandante do Batalhão de Operações Especiais (BOPE), que atuava na cena do seqüestro" Folha de S. Paulo, 13 jun. 2000, C3, Cotidiano.

26 Isto é, 21 jun.2000, p. 30-32.

27 Capitão reformado do Exército. Folha de S. Paulo, 14 jun. 2000. Caderno Cotidiano, p. C12. Uma nota oficial da assessoria de imprensa do Governador do Rio, emitida logo após o desfecho do seqüestro, e reproduzida em vários jornais impressos, sugere que uma rede de contatos havia sido estabelecida durante o seqüestro. 
A morte do seqüestrador dentro do carro da polícia que o conduzia à delegacia é a segunda mais importante controvérsia presente na cobertura da mídia impressa. O laudo da perícia médica indicou que Sandro do Nascimento chegou ao hospital já morto, por asfixia. O então governador do Rio nomeia, imediatamente, o problema: "a polícia asfixiou o bandido. Isso é intolerável, não tem cabimento em lugar nenhum"28. O Secretário de Segurança Pública do Rio declara: "estamos convencidos de que foi praticado um crime no trajeto e os cinco policiais que o acompanhavam já estão presos no quartel do Bope e serão indiciados" ${ }^{29}$.

Manter a restrição legal ao arbítrio policial no uso de violência é crucial para proteger os direitos e liberdades civis potencialmente ameaçados pelo abuso ou exercício excessivo de poder pela organização do Estado (Bobbio, 1988, p. 42). Devido ao fato de terem sido acusados de cometerem um crime, os policiais envolvidos retiram-se da cena pública e há um progressivo silenciamento de suas vozes. Advogados passam a falar por $\operatorname{eles}^{30}$. Como se sabe, o direito à privacidade, de retirar-se da cena pública, bem como o direito ao silêncio são resguardados pela lei (Arato, 2002, p. 28; Gutmann e Thompson, 1996, p. 105). Interessa ressaltar que, mesmo nesse caso, a retração da esfera de visibilidade pública não é completa. Dentro do sistema de direitos e deveres, exige-se que os representantes das instituições respondam às objeções levantadas pelos outros poderes ou continuem a dar respostas ao público. Caso contrário, eles podem perder o status público como responsáveis (accountable) diante de uma audiência ampliada. Pode-se dizer que o jornalismo, nesses casos, estabelece mecanismos para que os representantes políticos ou agentes oficiais a) estabeleçam uma accountability permanente diante de uma platéia ampliada e b) engajem-se em uma comunicação generalizada com outros interlocutores envolvidos na questão.

Os advogados alegam que o seqüestrador resistiu à prisão e os policiais não possuíam algemas para imobilizá-lo. Os advogados reafirmam que os cincos policiais

\footnotetext{
28 Garotinho. Folha de S. Paulo, 14 jun. 2000. Cotidiano, p. C7, C12.

$29 \quad$ Folha de S. Paulo, 14 jun. 2000. Cotidiano, p. C6.

$30 \quad$ Folha de S. Paulo, 22 jun. 2000. Cotidiano, p. C4.
} 
militares agiram "no estrito cumprimento do dever e em legítima defesa"31. Eles estariam, de tal forma, procurando defender "a própria vida e também a da sociedade” ${ }^{\# 2}$. No processo de discussão pública, há um reduzido espaço para a argumentação. Os membros da corporação policial não se negaram arbitrariamente ao diálogo, mas eles ficaram enclausurados na repetição de regras formais, seguindo padrões convencionais de justificação.

A visibilidade constituída pelos meios de comunicação é feita de uma pluralidade de agentes, de modo que ninguém pode constituí-la de uma maneira exclusiva ou isolada. O jornalismo confere visibilidade a diversos atores que podem contradizer um pronunciamento oficial, reunindo esforços para amplificar o processo de accountability. Uma forte suspeita é levantada sobre o discurso daqueles que defendiam a polícia e controvérsias foram geradas em torno de evidências acerca da inocência dos policiais. $\mathrm{Na}$ sociedade brasileira, uma percepção geral e uma acumulação de evidências empíricas apontam para o fato de que a violência policial faz parte do procedimento policial rotineiro $^{33}$. Os próprios relatórios do setor de Ouvidoria da Polícia de grandes cidades (como o Rio de Janeiro, Belo Horizonte e São Paulo) confirmam a gravidade da violência abusiva exercida tanto pela polícia civil quanto pela polícia militar (Sapori e Souza, 2001, p. 176). O regime de accountability, nesse sentido, está também ligado a um conjunto de expectativas, as quais os cidadãos produzem, com relação ao funcionamento das instituições, enquanto um processo coletivo e histórico (Manin, 1997; Przeworski, Stokes e Manin, 1999; Arato, 2002).

Pode-se indagar, então, como o jornalismo contribui para o processo de accountability, quando as instituições são ineficazes ou não se mostram interessadas em conduzir uma investigação mais aprofundada. No caso da polícia do Rio, como definido

31 Chaia Ramos eDaniele Braga. Estado de Minas, 13 jun. 2000, nacional, p. 7; Folha de S. Paulo, 16 jun. 2000, C1, Cotidiano.

32 Chaia Ramos eDaniele Braga. Estado de Minas, 13 jun. 2000, nacional, p. 7; Folha de S. Paulo, 16 jun. 2000, C1, Cotidiano.

33 Estudos apontam que práticas ilegais (como intimidação e retaliação de suspeitos, prisões sem justificativa, violação da integridade física dos prisioneiros, etc.) são desejadas pelas classes populares (Cardia, 1999; Zaluar, 1999: 9; Adorno, 1993; 1998). Há um grande número de mortes com características de uma execução, "entre eles [os suspeitos] que, uma vez rendidos, resistem à captura ou tentam escapar" (Avritzer, 2002:115). 
por Luis Eduardo Soares, então Secretário de Segurança do Estado do Rio, "estamos diante de um universo corporativista fechado, fortemente marcado por comprometimentos e cumplicidades degradantes, com uma imagem pública negativa, atado a tradições autoritárias e burocratizantes, infenso ao planejamento, à avaliação, refratário ao controle externo e insensível às demandas da sociedade" (Soares, 2000, p. 148). Primeiramente, deve-se ter em mente que a função política dos media é operar como um mecanismo de publicidade, e ela não deve ser vista como responsável pelas falhas de outras instituições. Se os media assumem atributos de outras instituições do sistema político, como o Congresso ou o sistema judiciário, eles lançam sombras na divisão constitucional do poder, causando danos à vida democrática. O jornalismo, no melhor dos casos, oferece informações acuradas ao olhar público, as quais podem (ou não) fazer deslanchar investigações formais e ações legais (Waisbord, 2000, p. 241). Em segundo lugar, a troca de pontos de vista e argumentos na esfera de visibilidade pública coloca em movimento lutas e interações dramáticas entre representantes políticos e cidadãos. Isso pode mudar o contexto de entendimento dos problemas sociais e o modo de elaborar um planejamento inteligente. $\mathrm{Na}$ próxima seção, explorarei outras possibilidades proporcionadas pela visibilidade midiática com relação à inovação institucional.

\section{Vozes de atores críticos da sociedade civil}

Se os discursos da corporação policial tentam individualizar o episódio do ônibus 174 - o que é importante para o restabelecimento das condições da accountability política os agentes da sociedade civil procuram generalizar o acontecimento, entendendo-o como parte de uma série de casos semelhantes. Organizações voluntárias para a proteção dos direitos humanos, como a "Anistia Internacional" e o Human Rights Watch, representantes de Conselhos Comunitários de Segurança Pública ou movimentos sociais, como "Sou da Paz" e "Viva Rio", buscam, acima de tudo, apontar padrões recorrentes de abuso da força policial. Eles denunciam a opacidade dos procedimentos administrativos de rotina e o privilégio da justiça corporativa, conhecido por ser lento e formal. Eles ressaltam a ineficácia dos mecanismos de accountability desta instituição, uma vez que a punição da polícia é constantemente negada. A representante da organização Human Rights Watch no 
Brasil, por exemplo, declara em uma entrevista que o evento se constitui em uma "possibilidade de o governo brasileiro se posicionar e mudar o histórico de impunidade do país. [...] Segundo ela, apesar do crime praticado pelo seqüestrador, ele tinha direito à defesa na Justiça. [...] $]^{334}$. O sistema judiciário torna a condenação de policiais por crimes violentos praticamente impossível.

No debate público sobre o episódio do ônibus 174, o qual se desenvolveu na mídia impressa, os atores da sociedade civil pareciam menos preocupados em restabelecer a coordenação da responsabilidade pessoal ou profissional, e mais interessados em tematizar as falhas do modelo corrente de polícia, assim como as constelações de poder que impedem a prestação de contas da corporação policial. Segundo Habermas, esta é uma situação na qual os atores operam com "consciência da crise": ao invés de procurar por soluções imediatas para conflitos pontuais, eles buscam lançar, na cena pública, controvérsias "em torno de aspectos normativos dos problemas em questão" (Habermas, 1996, p. 357). Eles, então, "procuram influenciar sensibilidades para a alocação de responsabilidades políticas" (Habermas, 1996, p. 357). Os discursos de atores críticos e associações cívicas chamavam particularmente a atenção para setores institucionais que necessitavam urgentemente de reformas.

Como apontado anteriormente, o processo de accountability pressupõe a existência de uma conexão entre a configuração dos arranjos institucionais e as necessidades dos cidadãos. Se os representantes negligenciam os anseios do público e sistematicamente resistem às demandas de prestação de contas, eles perdem legitimidade. Como diz Habermas,

Durante os processos de sintonização, não pode romper-se o laço da delegação de competências de decisão. Somente assim é possível conservar o vínculo com o público de cidadãos, os quais têm o direito e se encontram na condição de perceber, identificar e tematizar publicamente a inaceitabilidade do funcionamento de determinados sistemas sociais (Habermas, 1997, p. 83).

Contudo, é importante perceber que, mesmo quando o procedimento de sintonia fracassa, a prática de trocar de visões, argumentos e críticas que se inicia fora das instituições $34 \quad$ Folha de S. Paulo, 15 jun. 2000. Caderno Cotidiano, p. C1. 
prepara o caminho para a renovação dessas mesmas instituições. Como Bohman (2000, p. 201) discute,

A deliberação dentro de instituições meramente re-arranja, ao invés de modificar, o conjunto de instalações, dispositivos e alternativas disponíveis. Quando a deliberação e o modo 'normal' de resolver problemas mostram-se bloqueados, o público não pode mais deliberar de modo restrito, confinado aos desenhos institucionais existentes (grifos meus).

Nesse sentido, os media desenvolvem um papel crucial como fórum para o debate cívico. As vozes dos líderes de movimentos sociais que combatem a violência e defendem os direitos humanos criticam o problema da violência policial, caracterizando-o como endêmico. Politizam também a questão da violência urbana, ampliando as perspectivas éticas e morais para se compreender o problema. Nas palavras de Mansbridge (1999, p. 215), "politizar [...] é trazer [a questão] à atenção do público, como algo que o público deve discutir enquanto coletividade, com a perspectiva de uma possível mudança". Agindo de uma maneira relativamente independente, as associações cívicas ainda contribuem para a busca ativa de soluções. Por exemplo, após o episódio do ônibus 174, várias demonstrações populares em cidades de todo o país foram cobertas pelos meios de comunicação de massa. Uma instituição não-governamental (Sou da Paø) organizou uma campanha nacional ("Basta! Eu quero paz") estruturada em três principais frentes: (i) promoção de debates, em todo o país, sobre vários aspectos da violência, reunindo especialistas, assim como consultores, associações de bairro e líderes de comunidades pobres; (ii) organização de ações de mobilização social em prol do desarmamento e do controle radical do uso de armas de fogo (pelos criminosos, pela polícia e pela população em geral); (iii) desenvolvimento de mecanismos para a cooperação entre o sistema de segurança pública e a sociedade civil, através de ações comunitárias. Vozes de atores críticos que combatem a violência diariamente, incluindo aquelas organizações cívicas localizadas em bairros pobres, providenciam um conhecimento prático para processar o problema da violência urbana.

É difícil apreender os efeitos da cobertura midiática de tais iniciativas e mobilizações cívicas. Para captar tais efeitos, seria preciso conduzir uma pesquisa 
específica. O que precisa ser aqui enfatizado para o desenvolvimento de meu argumento é o fato de que os media auxiliam a expandir discussões que ocorrem nos fóruns de associações cívicas, através da divulgação de idéias que, de outra forma, permaneceriam invisíveis ou limitadas ao ambiente privado de pequenos grupos. Há boas evidências de que o debate público, conduzido através dos meios de comunicação, auxilia a mudar o contexto do próprio debate e o modo como os representantes referem-se a interpretações de problemas feitas pelos cidadãos e indicam ações para a solução de conflitos. Quando os debates são desenvolvidos em uma base plural, torna-se claro que nenhum agente específico possui todas as informações e que ninguém possui de antemão a solução correta. Informações e soluções precisam ser construídas coletivamente (Bohman, 1996, p. 189; Gutmann e Thompson, 2004, p. 32; Fishkin, 1991, 1997). Representantes e agentes oficiais podem aprender sobre opções possíveis de ação, trazidas à tona durante o processo de troca argumentativa em público, as quais eles, de outro modo, poderiam ignorar.

A extensão dos debates na sociedade civil também auxilia a legitimar as escolhas políticas governamentais. Seja por oportunismo político ou não, na mesma semana na qual ocorreu o seqüestro do ônibus 174, o Presidente da República decidiu antecipar o anúncio do Plano de Segurança Nacional - um ambicioso plano envolvendo 124 ações, com propostas e programas dirigidos a todos os elos da criminalidade, desde programas destinados à segurança do cidadão, à polícia, ao Ministério Público e à justiça criminal, até o setor sócio-educativo de reabilitação de indivíduos em conflito com a lei e do Sistema Nacional Penitenciário. O Plano, implementado em 2000, evidencia o compromisso do governo federal com a questão da segurança pública, com uma significante concessão de recursos para unidades sub-nacionais (IPEA, 2003, p. 97).

\section{Considerações finais}

Os media operam como um importante mecanismo de publicidade. Eles são essenciais, em primeiro lugar, para a constituição pública de eventos, como o caso aqui analisado. As organizações da mídia expandem a comunicação, antes restrita a um contexto especificamente localizado no espaço e no tempo. Os meios de comunicação possuem uma capacidade única de conectar discursos de atores de diferentes setores da sociedade, 
tanto no plano nacional quanto no âmbito internacional. Ao envolver vários atores representantes políticos, autoridades públicas, especialistas, líderes de associações cívicas, cidadãos - as organizações midiáticas permitem o compartilhamento de informações e a troca de pontos de vista de uma maneira ampliada, catalisando processos de debate público.

Em segundo lugar, expressar e trocar interpretações publicamente pode alterar o modo pelo qual os representantes adquirem ou usam o conhecimento acerca do desempenho das instituições e seus agentes. Como em uma atividade dialógica, aqueles que se expressam na esfera de visibilidade pública podem incorporar e interpretar as contribuições dos outros segundo seus próprios termos; adotar um vocabulário que não era utilizado previamente; alterar julgamentos e a maneira de se expressarem. Se, imediatamente após o fim do seqüestro, o Governador do Rio elogiou a ação "enérgica" da polícia e considerou que o episódio teve "o melhor desfecho possível", tal avaliação foi drasticamente alterada:

Garotinho [...] mudou de idéia e classificou a [ação da polícia] como um fracasso, 'um desfecho desastroso, foi a pior coisa que poderia ter acontecido'..$^{35}$

Antes ele tinha uma visão, depois examinou os fatos, olhou as fotos e mudou de posição e classificou-a como um fracasso e trocou a chefia da PM. Fez incontáveis reuniões. Criticou sua polícia e prometeu verbas, programas e ações especiais, além de indenizar os parentes de Geísa. ${ }^{36}$

Contudo, o que acontece dentro das instituições após a exposição pública está apenas tangencialmente conectado com os media. As instituições possuem uma dinâmica própria. Os mecanismos de prestação de contas dependem de uma rede de instituições, que se articulam dependendo de fatores tais como: a natureza da instituição e sua relação com os poderes públicos para desencadear mecanismos formais de accountability; os padrões de negociações e compensações dos interesses em conflito; o grau de suporte público envolvendo uma dada questão, etc.

35 Estado de Minas, 14 jun. 2000. Caderno Política, p. 3; Folha de S. Paulo, 16 jun. 2000. Caderno Cotidiano, p. C12.

$36 \quad$ Isto É, 21 jun. 2000, p. 31. 
O jornalismo possui um papel importante na publicização dos atos de representantes políticos, e na forma como são conduzidas as investigações. Expor escândalos não é o suficiente para eliminá-los ou para que os representantes tornem-se responsáveis por seus atos ou, ainda, para que as instituições competentes desencadeiem processos de investigação e de punição. Como vimos, a exposição nos meios de comunicação constrange os representantes políticos ou as autoridades públicas a responder e a explicar suas próprias ações e omissões, tornando as ações abertas ao escrutínio e à avaliação externa. Em outras palavras, os media não criam a accountability, mas ajudam a adicionar esforços para criar uma sociedade mais vigilante e crítica. Ao se desenrolar na cena pública, a dinâmica de prestações de contas permite ao público julgar o desempenho dos representantes políticos e avaliar a efetividade das instituições que monitoram abusos e perpetram sanções aos transgressores. Se os políticos têm a intenção de se reeleger, eles não podem se afastar, sem sérias conseqüências, das opiniões e dos interesses dos cidadãos. Nesse sentido, a mediação da discussão pública ajuda os políticos a "testar as conseqüências do abandono de certos programas e promessas, reverter o curso quando necessário, e tentar persuadir o público através de palavras e atos” (Arato, 2002, p. 97).

A troca pública de visões - sustentadas na esfera de visibilidade pública, incluindo vários atores - pode modificar o contexto do entendimento dos problemas e o modo de formular as políticas públicas. Como busquei evidenciar, as vozes críticas advindas de movimentos sociais e associações voluntárias auxiliam na construção de uma definição compartilhada do abuso de poder da polícia como um problema estrutural da sociedade brasileira. Esses movimentos e associações assumem uma posição ativa com relação à questão em pauta e organizam ações em vários campos, a fim de combater as intrincadas causas da violência urbana. Ao mobilizarem os cidadãos, os movimentos sociais e as organizações voluntárias somam esforços para solucionar problemas que não podem ser resolvidos sem a cooperação dos próprios cidadãos. Obviamente, os media operam atendendo a lógicas e a modos próprios de operação. Além disso, eles nem sempre se interessam em estabelecer debates democráticos plurais, sobretudo para a expressão de idéias dos atores da sociedade civil. Reconhecer os modos pelos quais a publicidade constituída pelos meios de comunicação contribui para fomentar processos de 
accountability revigora o interesse em buscar saber como tornar os próprios media mais accountable nas sociedades democráticas.

Este artigo apresenta resultados parciais do projeto de pesquisa intitulado "Mídia, Democracia e Dimensões da Deliberação", financiado pelo CNPq e pela FAPEMIG. Um agradecimento é devido a Gisele Gomes de Almeida pela preciosa colaboração na tarefa de reunir e classificar o material empírico aqui analisado.

\section{Referências Bibliográficas}

ADORNO, Sérgio. A Criminalidade Urbana Violenta no Brasil - Um recorte temático. $B I B$, v. 35, p. 3-24, 1993.

ADORNO, Sérgio. Conflitualidade e violência: reflexões sobre a anomia na contemporaneidade. Tempo Social, v. 11, n. 2, p. 129-153, 1998.

ARATO, Andrew. Representação, Soberania Popular e Accountability. Lua Nova, v. 55-56, p. 85-103, 2002.

ARENDT, Hannah. Da violência. Brasília: Ed. UnB, 1985.

AVRITZER, Leonardo. Democracy and public space in Latin América. Princeton: Princeton University Press, 2002.

BEATO FILHO, Cláudio C. Informação e desempenho policial. Teoria e Sociedade, v. 7, p. 117-150, 2001.

BELLI, Benoni. Polícia, 'tolerância zero' e exclusão social. Novos Estudos Cebrap, v. 58, p. 157-172, 2000.

BENNETT, Lance W. et al. Managing Public Sphere: Journalistic Construction of the Great Globalization Debate. Journal of Communication, p. 437-454, Sept. 2004.

BOBBIO, Nobert. Liberalism and democracy. London: Verso, 1988.

BOHMAN, James. Public deliberation: pluralism, complexity and democracy. Massachusetts: MIT Press, 2000.

CALDEIRA, César. Segurança pública e seqüestros no Rio de Janeiro (1995-1996). Tempo Social, v. 9, n. 1, p. 115-153, 1996.

CARDIA, Nancy. Atitudes, normas culturais e valores em relação à violência em dez capitais brasileiras. Brasília: Ministério da Justiça/Secretaria do Estado de Direitos Humanos, 1999.

COHEN, Joshua. Deliberation and democratic legitimacy. In: BOHMAN, J.; REHG, W. (Eds.). Deliberative democracy. London: MIT Press, 1997. p. 67-92.

CURRAN, James. Rethinking media and democracy. In: CURRAN, J.; GUREVITCH, M. (Eds.). Mass media and society. Oxford: University Press, 2000. 
DAHLGREN, P. The Public sphere and the net: Structure, Space and Communication. In: BENNET, W. L.; ENTMAN, R. (Eds.). Mediated politics. Cambridge: Cambridge University Press, 2001. p. 33-56.

DENNIS, Evertt; GILLMOR, Donald; GASSER, Theodore L. (Eds.). Media freedom and accountability. New York: Greenwood Press, 1989.

DEWEY, John. The public and its problems. Chicago: Swallow Press, 1954.

FISHKIN, James. Democracy and deliberation. New Haven: Yale University Press, 1991.

FISHKIN, James. The voice of the people. New Haven: Yale University Press, 1997.

GAMSON, William; MODIGLIANI, Andre. Media discourse and public opinion on nuclear power: a constructionist approach. American Journal of Sociology, v. 95, n. 1, p. 1-37, 1989.

GUTMANN, Amy; THOMPSON, Dennis. The scope of accountability. In: GUTMANN, Amy; THOMPSON, Dennis. Democracy and disagreement. Cambridge: Harvard University Press, 1996. p. 128-164.

GUTMANN, Amy; THOMPSON, Dennis. Why deliberative democracy? Princeton: Princeton University Press, 2004.

HABERMAS, Jürgen. Between facts and norms. New Baskerville: MIT Press, 1996.

HARMON, Michel. Responsibility as paradox: A critique of rational discourse in government. Thousand Oaks, Cambridge: Sage Publications, 1995.

HAUSER, Gerard. Body rhetoric: conflicted reporting of bodies in pain. In: CHAMBERS, S.; COSTAIN, A. Deliberation, democracy and the media. London: Rowman \& Littlefield Publishers, 2000. p. 135-154.

HÖIJER, Birgitta. The discourse of global compassion: the audience and the media reporting on human suffering. Media, Culture \& Society, v. 26, n. 4, p. 513$531,2004$.

HUNOLD, Christian. Corporatism, pluralism and democracy: toward a deliberative theory of bureaucratic accountability. Governance: an international $J$. of Policy and Adm, v. 14, n. 2, p. 151-167, 2001.

INSTITUTO DE PESQUISA ECONÔMICA APLICADA (IPEA). Segurança Publica. Políticas Sociais - Acompanhamento e Análise, v. 6, p. 88-98, 2003.

LIMA, Roberto Kant de. A polícia do Rio de Janeiro: seus dilemas e paradoxos. Rio de Janeiro: Forense, 1995.

MANIN, Bernard. The principles of representative government. Cambridge: Cambridge University Press, 1997.

MANSBRIDGE, Jane. Everyday talk in deliberative system. In: MACEDO, S. (Ed.). Deliberative politics: essays on democracy and disagreement. Oxford: Oxford University Press, 1999. p. 211-242.

MAWBY, Rob. Continuity and Change, convergence and divergence: the Police and practice of police-media relations. Criminal Justice, v. 2, n. 3, p. 3003-3324, 2002. 
McADAM, Doug. Movement strategy and dramaturgic framing in democratic states: the case of the American civil rights movement. In: CHAMBERS, S.; COSTAIN, A. (Eds.). Deliberation, democracy and the media. New York, Rowman \& Littlefield Publishers, 1996. p.117-134.

MEYER, D. S. Framing national security: elite discourse on nuclear power during the Cold War. Political Communication, v. 12, p. 173-192, 1995.

MEYER, Thomas. Media democracy: how the media colonize politics. Cambridge: Polity Press, 2002.

MULGAN, Richard. 'Accountability': an ever-expanding concept?” Public Administration, v. 78, n. 3, p. 555-573, 2000.

NORRIS, Pipa. A virtuous circle - political communications in postindustrial societies. Cambridge: Cambridge University Press, 2000.

PAGE, Benjamin. Who deliberates? Mass media in modern democracy. London: University of Chicago Press, 1996.

PAN, Zhogdang; KOSICKI, Gerald M. Framing as strategic action in public deliberation. In: REESE, S. D. et al. (Eds). Framing public life: perspectives on media and our understanding of the social life. New Jersey: Lauwrence Erlbaum Publishers, 2003. p. 35-66.

PERALVA, Angelina. Violência e democracia: o paradoxo brasileiro. São Paulo: Paz e Terra, 2000.

PIAULT, Marc-Henri. Da violência, ou como se livrar dela. A propósito do seqüestro de um ônibus no Rio de Janeiro. In: BIRMAN, P.; LEITE, M. (Orgs.). Um mural para a dor - movimentos cívicos-religiosos por justiça e paz. Porto Alegre: Ed. UFRGS, 2004. p. 19-66.

PINHEIRO, Márcia Leitão. 2004. Da pacificação - 'O Basta! Eu quero Paz' e as inscrições artísticas”, in P. Birman \& M. Leite (Orgs.). Um mural para a dor movimentos cívicos-religiosos por justiça e paz. Porto Alegre, UFRGS.

PINHEIRO, Paulo Sérgio. Violência, crimes e sistemas policiais em países de novas democracias. Tempo Social, v. 9, n. 1, p. 43-53, 1997.

PRICHARD, David. The process of media accountability. In: PRICHARD, David (Org.). Holding the media accountable: citizens, ethics and the law. Bloomington: Indiana University Press, 2000. p.1-10.

PRZEWORSKI, Adam; STOKES, Susan; MANIN, Bernard. Democracy, accountability and representation. Cambridge: Cambridge University Press, 1999.

QUÉRÉ, Louis. L'espace public comme forme et comme événement. In: JOSEPH, I. (Org.). Prendre place: espace public et culture dramatique. Pontigny-Cerisy: Éditions Recherches, 1995. p. 93-110.

REESE, Stephen D. et al. (Eds). Framing public life: perspectives on media and our understanding of the social life. New Jersey: Lauwrence Erlbaum Publishers, 2003. 
ROBERTS, Nancy C. Keeping Public Officials Accountable through Dialogue:

Resolving the Accountability Paradox. Public Administration Review, v. 62, n. 6, p. 658-669, 2002.

ROMZEK, Barbara S.; DUBNICK, Melvin J. Accountability and the public sector: lessons from the challenger tragedy. Public Administration Review, v. 47, n. 3, p. 227-238, 1987.

SAPORI, Luís Flavio; SOUZA, Silas Barnabé. Violência policial e cultura militar: aspectos teóricos e empíricos. Teoria e Sociedade, p. 173-213, 2001.

SCHUDSON, Michael. The power of news. Cambridge: Harvard University Press, 1995.

SLAVKO, Splichal. The principle of pubicity, public use of reason and social control. Media, Culture \& Society, v. 24, p. 5-26, 2002.

SOARES, Luis E. Segurança Pública e direitos Humanos - Entrevista de Luiz Eduardo Soares a Adorno Sérgio. Novos Estudos Cebrap, v. 57, p. 141-154, 2000.

SOARES, Luis E. Violência e política no Rio de Janeiro. Rio de Janeiro: RelumeDumará, 1996.

THOMPSON, John B. Political scandal: power and visibility. Cambridge: Polity Press, 2000.

THOMPSON, John B. The media and modernity. Cambridge: Cambridge UP, 1995.

TUCHMAN, Gaye. Making news. A study in the construction of reality. New York: Free Press, 1978.

WAISBORD, Silvio. Watchodog journalism in South America: news, accountability and democracy. New York: Columbia University Press, 2000.

ZALUAR, Alba. A globalização do crime e os limites da explicação local. In: VELHO, G.; ALVITO, M. (Orgs.). Cidadania e violência. Rio de Janeiro: Ed. UFRJ/ FGV, 1996. p. 48-68.

ZALUAR, Alba. Um debate disperso: violência e crime no Brasil da redemocratização. São Paulo em Perspectiva, v. 12, n. 3, p. 3-17, 1999. 